\title{
Determinação de fatores da equação universal de perda de solo em Sumé, PB $^{1}$
}

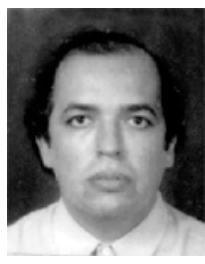

\author{
Abel W. de Albuquerque ${ }^{2}$, Gilson M. Filho², José R. Santos ${ }^{2}$, José P. V. Costa ${ }^{2}$ \& José L. Souza ${ }^{2}$ \\ 1 Trabalho financiado pelo CNPq \\ 2 Departamento de Solos e Engenharia - Centro de Ciências Agrárias-UFAL, CEP 57.100.100. Rio Largo, AL. \\ Tel/Fax: (082) 3261-2688. E-mail: awa@fapeal.br (Foto),gmf@fapeal.br, jrsantos2002@yahoo.com.br, jpvc@fapeal.br
}

Protocolo $145-16 / 9 / 2003$ - Aprovado em 1/7/2004

\begin{abstract}
Resumo: Para se alcançar os objetivos previstos neste trabalho, determinaram-se os fatores da Equação Universal de Perda de Solo (EUPS) em condições de chuva natural, num Luvissolo de Sumé, PB, em que os dados relativos aos anos de 1983-1990 foram obtidos na Estação Experimental de Sumé, PB, pertencente à Universidade Federal da Paraíba - UFPB, cujos tratamentos foram os seguintes: parcela descoberta e em alqueive contínuo, parcela com caatinga nativa, parcela com caatinga nova, parcelas em pousio, parcela com palma cultivada morro abaixo e parcela com palma cultivada em nível. Os valores médios anuais do fator erosividade da chuva expressos em El ${ }_{30}$ e $\mathrm{PI}_{30}$ foram de $4.928 \mathrm{MJ} \mathrm{mm} \mathrm{ha}^{-1} \mathrm{~h}^{-1}$ e $19.734 \mathrm{~mm}^{-2} \mathrm{~h}^{-1}$, respectivamente. Os valores do fator erodibilidade do solo (K) foram calculados em $0,013 \mathrm{t} \mathrm{h} \mathrm{MJ}^{-1} \mathrm{~mm}^{-1} \mathrm{e}$ $0,003 \mathrm{t} \mathrm{ha}^{-1} \mathrm{~mm}^{-2}$, enquanto os valores determinados para o fator uso e manejo do solo foram os seguintes: 0,0015 (caatinga nativa), 0,0174 (caatinga nova), 0,0133 (cobertura morta), 0,0056 (cobertura morta), 0,5103 (palma cultivada morro abaixo) e 0,2355 (palma cultivada em nível). O valor do fator práticas conservacionistas para palma cultivada em nível foi de 0,46.
\end{abstract}

Palavras-chave: erosividade, erodibilidade, erosão

\section{Determination of the factors of the universal soil loss equation in Sumé (Paraíba State, Brazil)}

\begin{abstract}
The Universal Soil Loss Equation (USLE) factors were determined in a Haplargs under natural rainfall conditions. Data concerning to the years of $1983-1990$ were obtained at the Sumé Experimental Station (Paraíba State - Brazil) of the Federal University of Paraíba (UFPB). The treatments consisted of runoff plots with bare soil, native semiarid vegetation runoff plot, mulch runoff plot, palm leaf under downhill runoff plot and under contour palm leaf runoff plot. The annual average of the rainfall erosivity factors $\mathrm{El}_{30}$ and $\mathrm{PI}_{30}$ were 4,928 $\mathrm{MJ} \mathrm{mm} \mathrm{ha}^{-1} \mathrm{~h}^{-1}$ and $19,734 \mathrm{~mm}^{-2} \mathrm{~h}^{-1}$, respectively. The calculated annual mean values of the erodibility parameters were calculated in $0.013 \mathrm{t} \mathrm{h} \mathrm{MJ}^{-1} \mathrm{~mm}^{-1}$ and $0.003 \mathrm{t} \mathrm{h} \mathrm{ha}^{-1} \mathrm{~mm}^{-2}$. The calculated values for the support practice factor cropping-management parameter were $0.0015,0.0174,0.0133,0.0056$, 0.5103 and 0.2355 for the native semiarid vegetation runoff plot, native semiarid vegetation (new) runoff plot, mulch runoff plots, downhill palm leaf runoff plot and contouring cropped palm leaf runoff plot treatments, respectively. The values of the support conservationist practice factor to downhill palm leaf runoff plot was 0.46 .
\end{abstract}

Key words: erosivity, erodibility, erosion

\section{INTRODUÇÃO}

A erosão é um fenômeno cujo impacto sobre os recursos naturais renováveis tem preocupado governos e instituições em todo o mundo. A magnitude deste fenômeno tem sido considerada uma ameaça à própria existência da humanidade (FAO, 1993). Esta ameaça tem contribuído para a urgência de se quantificar e controlar, de forma racional, as causas do processo erosivo. A necessidade de se determinar uma metodologia capaz de avaliar com precisão os fatores que causam a erosão e a estimativa das perdas de solo ocasionadas por tal ocorrência, tem resultado num grande número de pesquisas (Wischmeier \& Smith, 1978; Nearing et al., 1990 e Owoputi \& Stolte, 1995). Dentre essas metodologias, a Equação Universal de Perdas de Solo (EUPS) é uma das mais utilizadas, visto que permite a previsão das perdas de solo causadas pela erosão e 
indica quais os fatores que exercem os maiores efeitos sobre as perdas de solo (Albuquerque, 1997).

A EUPS, como atualmente é utilizada, foi desenvolvida a partir de 1953, quando o Soil and Water Conservation Research Division of the Agricultural Research Service reuniu, na Universidade de Purdue (EUA), dados de escoamento superficial e de perdas de solo de 48 estações experimentais localizadas em 26 Estados dos EUA. Com base nesses dados, incluíram-se inovações importantes que melhoraram a precisão da estimativa de perdas de solo, quais sejam: um índice de erosividade da chuva, um método para avaliação dos efeitos do manejo de uma cultura, um método para quantificar a erodibilidade do solo e um método para determinar os efeitos das interações de variáveis como: produtividade, seqüência de culturas e manejo dos resíduos culturais. As inovações introduzidas possibilitaram que as dificuldades concernentes a fatores de natureza climática ou geográfica existentes nas primeiras equações, fossem superadas, permitindo a sua aplicação em qualquer lugar onde os dados para o seu cálculo pudessem ser obtidos, sendo por isso mesmo chamada Equação Universal de Perdas de Solo (Wischmeier \& Smith, 1978).

Em relação às condições edafoclimáticas da região do Nordeste do Brasil, são escassos os trabalhos em que se estabeleceram as perdas de solo a partir da EUPS (Margolis, 1985 e Leprun, 1988). Dos fatores da EUPS, a erosividade é o que tem sido mais pesquisado (Chaves \& Diniz, 1981; Margolis \& Campos Filho, 1981; Margolis, 1985; Leprun, 1988; Catalince $\&$ Margolis, 1994). Os valores do fator erodibilidade do solo (K) obtidos através de chuva natural, são raros e, de forma geral, não seguem as recomendações da parcela padrão. Os resultados obtidos com simuladores de chuva são mais abundantes e, portanto, de maior contribuição para o estudo do fator K no Nordeste do Brasil, particularmente em sua região semi-árida (Leprun, 1988; Denardin, 1991 e Albuquerque, 1997).

Dados do fator uso e manejo do solo (C) foram obtidos no semi-árido do Estado de Pernambuco, abrangendo os solos Neossolo Regolítico eutrófico (Caruaru, PE) e Argissolo Vemelho-Amarelo (Glória do Goitá, PE). Para Caruaru, os valores do fator $\mathrm{C}$ variaram de 0,001 a 0,392 para o Capim-sempre-verde e algodão, respectivamente. Especificamente para a palma forrageira, o valor do fator $\mathrm{C}$ foi de 0,072 (Margolis \& Campos Filho, 1981; Margolis, 1985 e Margolis et al., 1991). Os resultados obtidos para o fator Práticas Conservacionistas indicam boas possibilidades de controle das perdas de solo, através de práticas simples e de fácil execução, como preparo do solo em contorno, alternância de capinas e faixas de vegetação permanentes, cujos valores foram de $0,64,0,17$ e 0,08, respectivamente (Margolis \& Mello Neto, 1977 e Margolis, 1985).
A determinação de fatores da equação universal de perdas de solo, nas condições do semi-árido do Nordeste do Brasil, contribuirá para que se tenha uma previsão das perdas de solo mais precisa, de forma que o planejamento do uso e manejo dos solos da região possa ser estabelecido com maior confiabilidade.

Objetivou-se, com este trabalho, determinar os fatores da EUPS nas condições de Sumé, PB.

\section{MATERIAL E MÉTODOS}

O trabalho foi desenvolvido na Estação Experimental de Sumé, PB, pertencente à Universidade Federal da ParaíbaUFPB, localizada na Fazenda Nova, município de Sumé-PB, situada no km 118 da BR-412, entre as cidades de Sumé e Monteiro, na latitude de $7^{\circ} 40^{\prime}$ Sul e longitude $37^{\circ} 00^{\prime}$ Oeste, com altitude entre 500 e $700 \mathrm{~m}$.

De acordo com a classificação de Köeppen, o clima da região é do tipo climático BSh, ou seja, seco, caracterizado por insuficiência e irregularidade das precipitações pluviais (Figura 1) e ocorrência de temperaturas elevadas (Cadier et al., 1983). A precipitação pluvial média anual no período de 1986 a 1990 foi de $695 \mathrm{~mm}$, com maior volume de chuvas concentrado nos meses de fevereiro a abril. A temperatura média anual no mesmo período foi de $24^{\circ} \mathrm{C}$ e a umidade relativa média anual de $57 \%$ (Cadier et al., 1983).

O solo no local do experimento é um Luvissolo Hipocrômico Órtico vértico, A fraco, textura argilosa fase caatinga hiperxerófila; suas características físicas e química encontrase na Tabela 1. A vegetação predominante na área do experimento é a caatinga hiperxerófila densa, cujo relevo se apresenta suavemente ondulado a fortemente ondulado, com declividade variando de 3,8 a 9,5\%.

Para a determinação dos fatores K, C e P, instalou-se um experimento constituído de sete parcelas experimentais com 22,13 m de comprimento por 4,52 $\mathrm{m}$ de largura (Wischmeir \& Smith, 1978), no qual foram instalados os seguintes tratamentos: Descoberto e em alqueive contínuo; Caatinga nativa; Caatinga nova; Pousio com cobertura morta; Palma cultivada morro abaixo e Palma cultivada em nível. As declividades médias das parcelas foram as seguintes: Descoberto e em alqueive contínuo: $0,040 \mathrm{~m} \mathrm{~m}^{-1}$, Caatinga nativa: $0,095 \mathrm{~m} \mathrm{~m}^{-1}$, Caatinga nova: $0,040 \mathrm{~m} \mathrm{~m}^{-1}$, Pousio com cobertura morta (1): $0,039 \mathrm{~m} \mathrm{~m}^{-1}$, Pousio com cobertura morta (2): $0,072 \mathrm{~m} \mathrm{~m}^{-1}$, Palma cultivada morro abaixo: $0,040 \mathrm{~m} \mathrm{~m}^{-1} \mathrm{e}$ Palma cultivada em nível: $0,040 \mathrm{~m} \mathrm{~m}^{-1}$.

A caatinga nova é um termo utilizado pelos agricultores para caracterizar a rebrota da caatinga após o seu corte; portanto, a caatinga foi cortada no início do experimento, para posterior rebrotamento. A parcela com caatinga nativa não sofreu

Tabela 1. Composição granulométrica e características químicas dos horizontes minerais de um Luvissolo, em Sumé, PB

\begin{tabular}{|c|c|c|c|c|c|c|c|c|c|c|c|c|c|c|c|c|}
\hline \multirow{3}{*}{ Horiz $^{1}$} & \multirow{3}{*}{$\begin{array}{c}\text { Prof }^{2} \\
\mathrm{~cm}\end{array}$} & \multicolumn{4}{|c|}{ Composição granulométrica } & \multirow{3}{*}{$\mathrm{pH}\left(\mathrm{H}_{2} \mathrm{O}\right)$} & & & Carc & cteríst & cas quí & icas & & & \multirow{3}{*}{$\begin{array}{l}\mathrm{V} \\
\%\end{array}$} & \multirow{3}{*}{$\begin{array}{l}\text { M.O } \\
\mathrm{g} \mathrm{kg}^{-1}\end{array}$} \\
\hline & & $\mathrm{AG}^{3}$ & $\mathrm{AF}^{4}$ & $\mathrm{Sil}^{5}$ & $\operatorname{Arg}^{6}$ & & $P$ & K & $\mathrm{Ca}$ & $\mathrm{Mg}$ & $\mathrm{Na}$ & $\mathrm{Al}$ & $\mathrm{H}$ & $\mathrm{T}$ & & \\
\hline & & \multicolumn{4}{|c|}{$\mathrm{g} \mathrm{kg}^{-1}$} & & $\mathrm{~g} \mathrm{k}_{\mathrm{g}}$ & \multicolumn{7}{|c|}{$\mathrm{cmol}_{\mathrm{c}} \mathrm{kg}^{-1}$} & & \\
\hline A & $0-10$ & 240 & 320 & 250 & 190 & 6,3 & 2,6 & 0,30 & 7,0 & 5,7 & 0,63 & 0,05 & 4,52 & 18,22 & 75 & 12,4 \\
\hline $2 \mathrm{Bt}$ & $10-50$ & 300 & 210 & 160 & 330 & 5,7 & 0,5 & 0,17 & 7,9 & 11,5 & 1,82 & 0,57 & 5,26 & 27,22 & 79 & 1,20 \\
\hline
\end{tabular}

${ }^{1}$ Horizontes, ${ }^{2}$ Profundidade, ${ }^{3}$ Areia Grossa, ${ }^{4}$ Areia Fina, ${ }^{5}$ Silte, ${ }^{6}$ Argila 
qualquer forma de intervenção. As parcelas em pousio com diferentes declividades foram roçadas quando a vegetação nativa atingiu a altura de $30 \mathrm{~cm}$, sem retirá-la de dentro das parcelas, objetivando-se a formação de uma cobertura morta, enquanto as parcelas com palma forrageira foram cultivadas com enxada morro abaixo e em nível, sendo que ambas as parcelas eram limpas sempre que a vegetação atingia $5 \mathrm{~cm}$ de altura. $\mathrm{O}$ manejo da parcela descoberta $(\mathrm{PW})$ e em alqueive contínuo seguiu as recomendações de Wischmeier \& Smith (1978), ou seja, a parcela foi mantida sem cobertura vegetal através do preparo e cultivo do solo no sentido do declive.

As parcelas foram delimitadas por chapas galvanizadas cravadas $15 \mathrm{~cm}$ no solo, e nas suas extremidades inferiores se instalaram sistemas coletores de enxurrada, constituídos de uma calha conectada por um cano de PVC a um primeiro tanque de fibrocimento, localizado imediatamente abaixo da parcela que, por sua vez, estava conectado ao segundo tanque de fibrocimento, através de um divisor de enxurrada do tipo "Geib".

Fez-se o registro diário das chuvas ocorridas no período de 1983 a 1990, utilizando-se um pluviógrafo do tipo IH, localizado na estação meteorológica adjacente ao experimento. Para o cálculo da energia cinética das chuvas foram cotadas as chuvas individuais erosivas em segmentos de intensidade constante, através do método proposto por Wischmeier \& Smith (1978) e os valores obtidos foram posteriormente transferidos para o programa computacional desenvolvido por Cataneo et al. (1982), onde foram calculados os valores da energia cinética e a erosividade da chuva expressa em $\mathrm{EI}_{30}$ e $\mathrm{PI}_{30}$. Os fatores $\mathrm{EI}_{30}$ e $\mathrm{PI}_{30}$ foram escolhidos pelas seguintes razões: 1) o fator $\mathrm{EI}_{30}$ tem-se apresentado como bom estimador das perdas de solo em diversos trabalhos realizados no Brasil, e 2) o fator $\mathrm{PI}_{30}$ que, por exigir apenas as informações do volume e da intensidade máxima da chuva e dispensar o cálculo da energia cinética, apresenta boa aplicabilidade, como se tem demonstrado em diversos trabalhos realizados no Brasil (Leprun, 1988; Catalince \& Margolis, 1994 e Albuquerque, 1997).

A equação utilizada para o cálculo da energia cinética e convertida para o Sistema Internacional de Unidades (Foster et al., 1981), foi aquela obtida por Wischmeier \& Smith (1978):

$$
\mathrm{Ec}=0,119+0,0873 \log \mathrm{I}
$$

em que: Ec é a energia cinética da chuva, em $\mathrm{MJ} \mathrm{ha}^{-1} \mathrm{~mm}^{-1}$, e I é a intensidade da chuva em cada segmento com intensidade constante $\mathrm{em} \mathrm{mm} \mathrm{h}^{-1}$. Para intensidades de chuva iguais ou superiores a $76 \mathrm{~mm} \mathrm{~h}^{-1}$, a energia cinética tem um valor máximo de $0,2832 \mathrm{MJ} \mathrm{ha}^{-1} \mathrm{~mm}^{-1}$.

A erodibilidade do solo $(\mathrm{K})$ foi definida como o incremento médio na perda de solo para cada unidade adicionada do fator $\mathrm{R}$, ou seja, $\mathrm{K}=\mathrm{A} \mathrm{R}^{-1}$, donde: $\mathrm{K}$ é o fator erodibilidade do solo, expresso numericamente pela relação entre a perda média anual de um solo mantido continuamente descoberto e o fator erosividade da chuva; A é a perda de solo obtida de uma parcela padrão, com as seguintes características: 9\% de declividade e 22,13 m de comprimento, mantida continuamente sem cobertura vegetal e cultivada morro abaixo, de forma a manter a superfície do solo livre de crostas e "R" é o fator erosividade da chuva.

As equações de regressão para a relação entre as perdas de solo e os fatores erosividade da chuva $\left(\mathrm{EI}_{30} \mathrm{e} \mathrm{PI}_{30}\right)$ foram obtidas através do programa estatístico SAS (SAS Institute, 1988). Para se verificar a homogeneidade entre os coeficientes de correlação, utilizou-se o teste proposto por Graybill (1961).

Os valores dos fatores topográficos (L e S), por sua vez, foram estimados com base na equação proposta por Wischmeier \& Smith (1978):

$$
\mathrm{LS}=\left(\frac{\sqrt{\mathrm{L}}}{100}\right)\left(1,36+0,97 \mathrm{~s}+0,1385 \mathrm{~s}^{2}\right)
$$

ou seja: L é o comprimento da rampa em m e sé a declividade expressa em $\%$.

Os valores do fator práticas conservacionistas $(\mathrm{P})$ foram determinados através da relação entre as perdas médias de solo verificadas nos tratamentos cultivado com palma em nível e plantio morro abaixo, respectivamente.

Após cada chuva as amostras da enxurrada eram retiradas dos tanques coletores das parcelas para a determinação das perdas de solo e água, de acordo com as recomendações de Cadier et al. (1983). As declividades médias das parcelas apresentadas quando da descrição dos tratamentos, foram diferentes, a saber: $0,040 \mathrm{~m} \mathrm{~m}^{-1}$ (descoberto, caatinga nova, palma cultivada morro abaixo e palma cultivada em nível), $0,095 \mathrm{~m} \mathrm{~m}^{-1}$ (caatinga nativa), $0,039 \mathrm{~m} \mathrm{~m}^{-1}$ (pousio 1) e $0,072 \mathrm{~m} \mathrm{~m}^{-1}$ (pousio 2). Para uma interpretação adequada dos resultados obtidos, as perdas de solo das referidas parcelas experimentais foram corrigidas para a declividade padrão, de $0,09 \mathrm{~m} \mathrm{~m}^{-1}$, através da equação de Wischmeier \& Smith (1978):

$$
\mathrm{S}=0,065+4,56 \operatorname{sen} \theta+65,41 \operatorname{sen}^{2} \theta
$$

sendo:

S - fator de correção do efeito da declividade local para as condições da EUPS;

$\theta$ - ângulo da declividade do terreno.

Portanto, as equações finais que possibilitaram a transformação direta das perdas de solo, foram as seguintes:

$$
\begin{aligned}
& \mathrm{A}_{0,09} \mathrm{~m} \mathrm{~m}^{-1}=0,53 \times \mathrm{A}_{0,095} \mathrm{~m} \mathrm{~m}^{-1} \\
& \mathrm{~A}_{0,09} \mathrm{~m} \mathrm{~m}^{-1}=1,692 \times \mathrm{A}_{0,039} \mathrm{~m} \mathrm{~m}^{-1} \\
& \mathrm{~A}_{0,09} \mathrm{~m} \mathrm{~m}^{-1}=0,78 \times \mathrm{A}_{0,072} \mathrm{~m} \mathrm{~m}^{-1} \\
& \mathrm{~A}_{0,09} \mathrm{~m} \mathrm{~m}^{-1}=2,83 \times \mathrm{A}_{0,040} \mathrm{~m} \mathrm{~m}^{-1}
\end{aligned}
$$

donde:

$\mathrm{A}_{0,090} \mathrm{~m} \mathrm{~m}^{-1}$ - perda de solo ocasionada por uma chuva qualquer, corrigida para o declive de $0,09 \mathrm{~m} \mathrm{~m}^{-1}$.

$\mathrm{A}_{0,095} \mathrm{~m} \mathrm{~m}^{-1}$ - perda ocasionada por uma chuva qualquer, ocorrida no declive de $0,095 \mathrm{~m} \mathrm{~m}^{-1}$ da parcela experimental. 
$\mathrm{A}_{0,039} \mathrm{~m} \mathrm{~m}^{-1}=$ perda ocasionada por uma chuva qualquer, verificada no declive de $0,038 \mathrm{~m} \mathrm{~m}^{-1}$ da parcela experimental.

$\mathrm{A}_{0,072} \mathrm{~m} \mathrm{~m}^{-1}=$ perda ocasionada por uma chuva qualquer, ocorrida no declive de $0,072 \mathrm{~m} \mathrm{~m}^{-1}$ da parcela experimental.

$\mathrm{A}_{0,040} \mathrm{~m} \mathrm{~m}^{-1}=$ perda ocasionada por uma chuva qualquer, ocorrida no declive de $0,040 \mathrm{~m} \mathrm{~m}^{-1}$ da parcela experimental.

Para a determinação do fator uso e manejo do solo, utilizouse a metodologia sugerida pelo Agriculture Handbook No 282 (Wischmeier \& Smith, 1965).

Considerando-se que a palma forrageira é uma cultura perene adotou-se, como critério para o estabelecimento dos estádios de desenvolvimento, a variação das razões de perdas de solo durante o desenvolvimento da mesma, as quais aumentaram até 60 dias após o plantio e diminuíram após 180 dias do plantio (DeMaria \& Lombardi Neto, 1997); desta forma, os seis estádios de desenvolvimento para a cultura da palma forrageira, que expressaram condições uniformes de proteção do solo e de seus efeitos de manejo, foram: 1) do preparo do solo até o plantio (dezembro-janeiro); 2) do fim do estádio 1 até 30 dias após o plantio (fevereiro); 3) do fim do estádio 2 até 60 dias após o plantio (março-abril); 4) do fim do estádio 3 até 180 dias após o plantio (maio-outubro) e 5) do fim do estádio 4 até 210 dias após o plantio (novembro)

A razão das perdas de solo foi calculada de acordo com a equação abaixo:

$$
\mathrm{RPSi}=\frac{\sum_{\mathrm{j}=1}^{8} \mathrm{PSm}}{\sum_{\mathrm{j}=1}^{8} \mathrm{PSd}}
$$

ou seja:

i é o estádio de cultura; RPSi é a razão de perdas de solo no estádio i; PSm é a perda de solo no tratamento m,. PSd é a perda de solo no tratamento mantido em alqueive contínuo e j é o número de anos.

$\mathrm{O}$ fator uso e manejo do solo (C) foi calculado pela seguinte equação:

$$
\mathrm{C}=\sum_{\mathrm{I}=1}^{8} \operatorname{RPSi} \frac{\mathrm{Ri}}{\mathrm{R}}
$$

em que:

Ri é a erosividade no estádio i e R é a erosividade anual.

\section{RESULTADOS E DISCUSSÃO}

\section{Fator erosividade da chuva (R)}

Os valores médios anuais dos fatores erosividade da chuva $\left(\mathrm{EI}_{30}\right.$ e PI $\left.{ }_{30}\right)$ e da precipitação pluvial foram de $4.928 \mathrm{MJ} \mathrm{mm} \mathrm{ha}^{-1} \mathrm{~h}^{-1}$, $19.734 \mathrm{~mm}^{2} \mathrm{~h}^{-1}$ e $695 \mathrm{~mm}$, respectivamente (Tabela 2A e B). Para efeito de comparação observa-se, na Figura 1, a distribuição dos valores anuais da erosividade da chuva $\left(\mathrm{EI}_{30}\right.$ e $\left.\mathrm{PI}_{30}\right)$ e da precipitação pluvial de Sumé, PB. A análise estatística, tanto dos valores anuais da precipitação pluvial quanto da

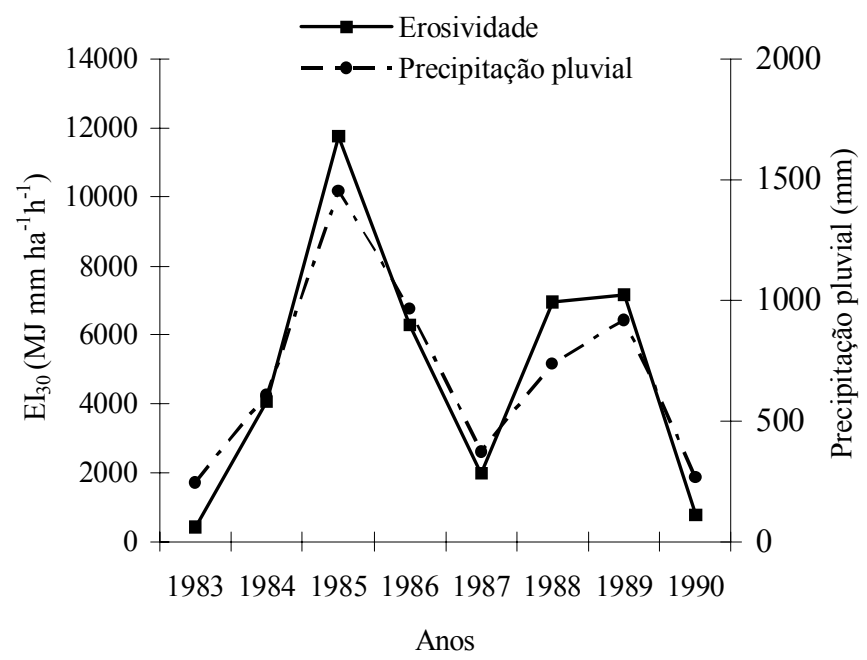

Figura 1. Distribuição dos valores anuais da erosividade da chuva e da precipitação pluvial em Sumé, PB

erosividade de Sumé, PB, indicou alta dispersão, conforme as tabelas referidas, a qual, confirmada pelos fatores estatísticos, reflete a irregularidade da precipitação pluvial anual, que é uma característica da região semi-árida como relatado por Albuquerque, (1997) e Albuquerque et al., (2001).

Constata-se, na Figura 2, que os maiores valores médios mensais, tanto da erosividade da chuva quanto da precipitação pluvial em Sumé, PB, ocorreram nos meses de fevereiro, março e abril como, também, 53 e 79\% da precipitação e da erosividade em Sumé, PB. A concentração de $79 \%$ da erosividade da chuva em apenas três meses é um indicador de que se deve tomar medidas preventivas no sentido de proteger o solo da erosão hídrica durante este período crítico do ano, corroborando com Albuquerque (1997) e Albuquerque et al. (2001).

As equações de regressão entre as perdas de solo e os fatores erosividade $\mathrm{EI}_{30}$ e $\mathrm{PI}_{30}$, foram as seguintes:

$$
\mathrm{A}=0,79664+0,01001 \mathrm{EI}_{30,} \quad(\mathrm{r}=0,74)
$$

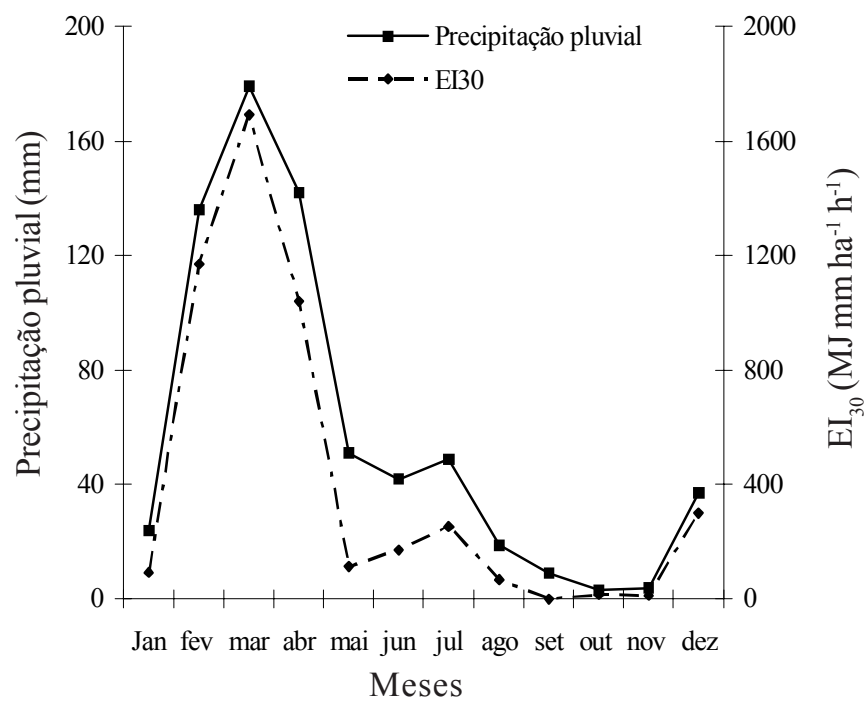

Figura 2. Distribuição temporal dos valores médios mensais da erosividade das chuvas e da precipitação pluvial em Sumé, PB 


$$
\mathrm{A}=0,64484+0,02582 \mathrm{PI}_{30,} \quad(\mathrm{r}=0,73)
$$

em que: A é a perda de solo e r é o coeficiente de correlação.

O teste de homogeneidade proposto por Graybill (1961), indicou não haver diferença estatística entre os coeficientes de correlação, razão por que os fatores erosividade $\mathrm{EI}_{30}$ e o $\mathrm{PI}_{30}$ podem ser estimados com o mesmo grau de precisão.

\section{Fator erodibilidade do solo (K)}

Tomando-se como base de cálculo os valores médios anuais obtidos para a erosividade da chuva $\left(\mathrm{EI}_{30}\right.$ e $\left.\mathrm{PI}_{30}\right)$, calcularam-se os valores da erodibilidade (K), em 0,013 th MJ $\mathrm{mm}$ e $0,003 \mathrm{th} \mathrm{ha} \mathrm{mm}^{-1}$, respectivamente.

$\mathrm{O}$ valor obtido para o fator $\mathrm{K}$ no presente trabalho $(0,013 \mathrm{t}$ $\mathrm{h} \mathrm{MJ}^{-1} \mathrm{~mm}^{-1}$ ) é considerado baixo, de acordo com a classificação estabelecida por Foster et al. (1981), enquanto os valores de K calculados por Denardin (1991) para dois Luvissolos foram de 0,008 e $0,044 \mathrm{th} \mathrm{MJ}^{-1} \mathrm{~mm}^{-1}$; portanto, o valor obtido para o referido fator no presente trabalho, ocupa posição intermediária entre os dois valores de K obtidos por Denardin (1991). Podese, também, constatar que o valor do fator K obtido para o solo Luvissolo de Sumé, PB, se encontra dentro da amplitude de valores obtidos para solos com B textural, como os Argissolos e Planossolos $\left(0,004\right.$ a $\left.0,031 \mathrm{t} \mathrm{h} \mathrm{MJ}^{-1} \mathrm{~mm}^{-1}\right)$, conforme relatado por Denardin (1991); por outro lado, o valor de K obtido neste trabalho foi maior que os encontrados por Silva et al. (1986) para solos Neossolos $\left(0,005\right.$ a $\left.0,008 \mathrm{th} \mathrm{MJ}^{-1} \mathrm{~mm}^{-1}\right)$.

O baixo valor da erodibilidade do solo foi devido, provavelmente, à presença do pavimento desértico, que é uma característica dos solos Luvissolos, constituídos de calhaus e matacões de quartzo, que servem como agente protetor, interceptando o impacto das gotas de chuva sobre o solo e, por conseguinte, interferindo diretamente no processo erosivo. Segundo Silva et al. (1986), o baixo valor obtido $\left(0,006 \mathrm{th} \mathrm{MJ}^{-1}\right.$ $\mathrm{mm}^{-1}$ ) para o fator $\mathrm{K}$ de um Luvissolo não diferiu daqueles

Tabela 2. Valores mensais, médios mensais, anuais e médio anual da erosividade da chuva $\left(\mathrm{EI}_{30}\right)$ e $\left(\mathrm{PI}_{30}\right)$ da precipitação pluvial de Sumé, PB, correspondente ao período de 1983 a 1990

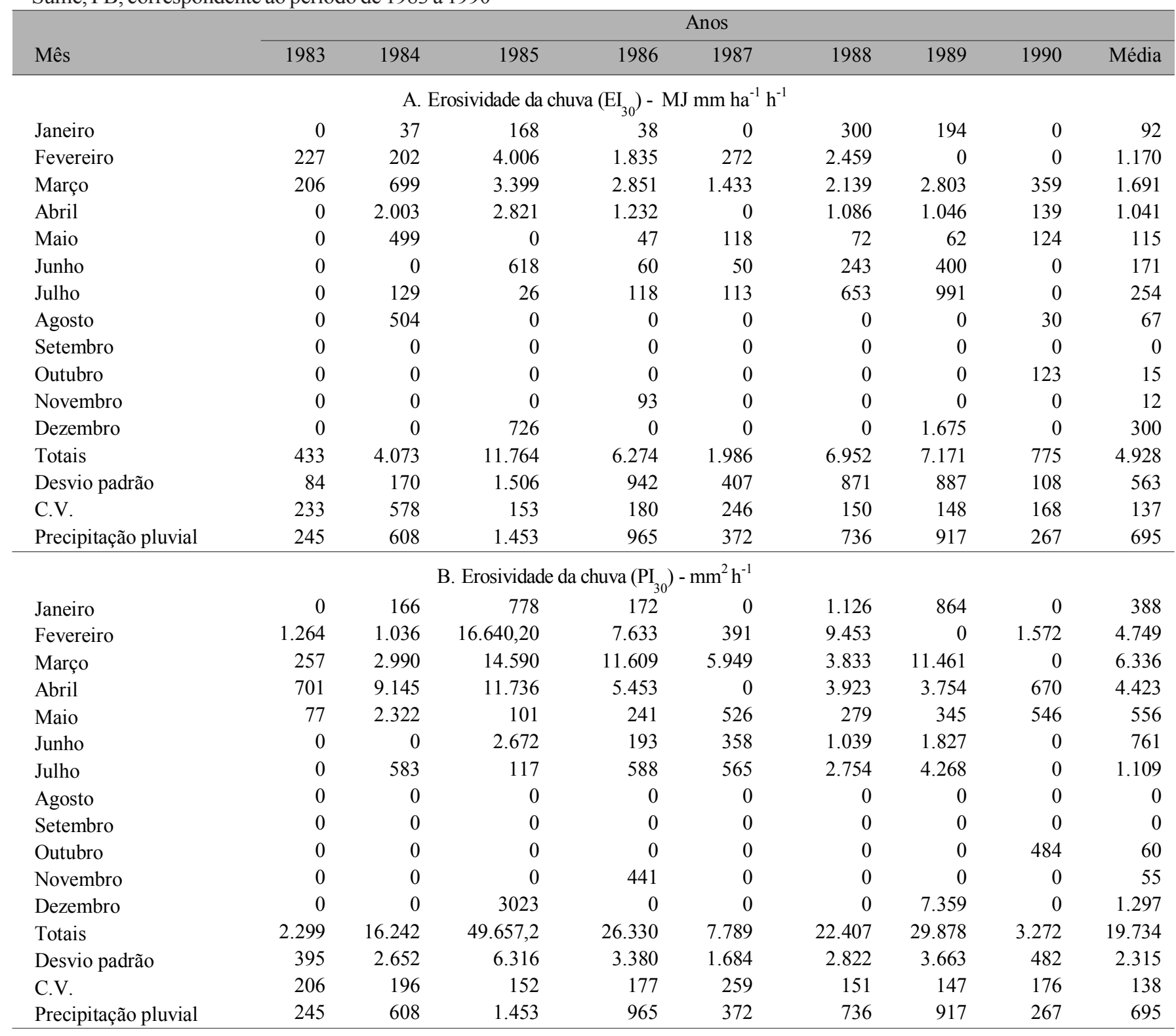


encontrados para os Neossolos, devido ao fato de que o pavimento desértico do Luvissolo, ao interceptar as gotas de chuva atenuou a ação desagregadora do seu impacto sobre a superfície do solo, contribuindo para que apresentasse comportamento idêntico ao Neossolo.

Com relação ao fator $\mathrm{K}$ deve-se ressaltar que o mesmo foi estabelecido a partir dos vinte e três principais solos dos EUA, excetuando-se os Vertissolos e os solos pedregosos, como no caso dos Luvissolos (Wischmeier \& Smith, 1978); então, para solos rasos, com montmorilonita dominante e fase pedregosa, a EUPS tem que ser aplicada com cautela.

\section{Fator uso e manejo do solo (C)}

O efeito da cobertura vegetal sobre as perdas médias anuais de solo contribuiu para que as mesmas fossem reduzidas de 65,37 t ha ${ }^{-1}$ (Parcela padrão) para 0,37 t ha- (Pousio 2), representando uma redução de $99,43 \%$ nas perdas de solo, Tabela 3. Os valores obtidos para o fator $\mathrm{C}$ variaram de 0,0014 a 0,5429 para a caatinga nativa e palma forrageira morro abaixo, respectivamente (Tabela 4).

Os resultados apresentados na Tabela 3 indicam um controle eficiente da erosão por parte da cobertura vegetal oferecida pela caatinga nativa; este fato está associado, provavelmente, à extraordinária capacidade de rebrote da caatinga, por ocasião das primeiras chuvas, formando um dossel semelhante a uma floresta baixa, capaz de atenuar os efeitos do impacto das gotas de chuva sobre o solo. Durante a estação seca, por outro lado, a caatinga hiperxerófila, por ser decídua, contribui para a formação de uma camada de folhas sobre a superfície, atenuando não apenas o impacto das gotas de chuva mas, também, o escoamento superficial sobre o solo (Mendes, 1986; Reis, 1988 e Albuquerque et al., 2001).

A palma cultivada morro abaixo (Tabela 4) foi a cobertura vegetal que proporcionou a menor proteção contra a erosão $(C=0,5429)$, enquanto aquelas com caatinga nativa, pousio e caatinga nova, foram as que ofereceram a maior proteção ao solo $(\mathrm{C}=0,0178,0,0128,0,0120 \mathrm{e} 0,0014)$. Os valores do fator $\mathrm{C}$ obtidos para a palma forrageira $(0,2528$ e 0,5429$)$ foram, em geral, maiores que os obtidos em Caruaru, $\mathrm{PE}(\mathrm{C}=0,072)$ por Margolis et al. (1985). Esses resultados são devidos a dois aspectos: 1) ao fato do Luvissolo no local do experimento apresentar maior susceptibilidade à erosão, quando comparado com o Neossolo Regolítico de Caruaru, PE; 2) em virtude da precipitação pluvial $(695 \mathrm{~mm})$ e da erosividade da chuva (4.928 $\left.\mathrm{MJ} \mathrm{mm} \mathrm{ha}^{-1} \mathrm{~h}^{-1}\right) \mathrm{em}$ Sumé, PB, serem mais limitantes, quando comparadas com aquelas de Caruaru, PE (725 mm e $2.100 \mathrm{MJ} \mathrm{mm} \mathrm{ha}^{-1} \mathrm{~h}^{-1}$ ).

Os valores obtidos do fator $C$ para Caatinga Nativa $(0,0014)$ e Caatinga Nova $(0,0178)$ evidenciaram a eficiência da vegetação nativa no controle das perdas por erosão (Tabela 4). Os resultados obtidos para a caatinga foram semelhantes àqueles dos tratamentos em pousio com cobertura morta $(0,0128 \mathrm{e}$ 0,0120). Os baixos valores do fator $\mathrm{C}$ obtidos para os tratamentos em pousio com cobertura morta indicam a importância desta prática no controle das perdas de solo no semi-árido nordestino.

O maior valor do fator "C" obtido para a parcela com caatinga nova, quando comparado com aquela com caatinga nativa, foi explicado pelo fato de que a caatinga nova foi cortada

Tabela 3. Valores das perdas médias de solo (PS) e da razão de perdas de solo (RPS) nos diferentes estádios de desenvolvimento das culturas e de uso e manejo do solo

\begin{tabular}{|c|c|c|c|c|c|c|c|c|c|c|c|c|}
\hline \multirow{3}{*}{ Cobertura vegetal } & \multicolumn{12}{|c|}{ Estádio de desenvolvimento das culturas* } \\
\hline & \multicolumn{2}{|c|}{1} & \multicolumn{2}{|c|}{2} & \multicolumn{2}{|c|}{3} & \multicolumn{2}{|c|}{4} & \multicolumn{2}{|c|}{5} & \multicolumn{2}{|c|}{ Total } \\
\hline & $\begin{array}{l}\text { PS } \\
\mathrm{t} \mathrm{ha}^{-1}\end{array}$ & RPS & $\begin{array}{c}\text { PS } \\
\mathrm{t} \mathrm{ha}^{-1}\end{array}$ & RPS & $\begin{array}{c}\text { PS } \\
\mathrm{t} \mathrm{ha}^{-1}\end{array}$ & RPS & $\begin{array}{l}\text { PS } \\
\mathrm{t} \mathrm{ha}^{-1}\end{array}$ & RPS & $\begin{array}{l}\text { PS } \\
\mathrm{t} \mathrm{ha}^{-1}\end{array}$ & RPS & $\begin{array}{c}\text { PS } \\
\mathrm{t} \mathrm{ha}^{-1}\end{array}$ & RPS \\
\hline Parcela padrão & 7,92 & - & 11,60 & - & 38,43 & - & 7,41 & - & 0,00 & -- & 65,37 & 1,00 \\
\hline Caatinga nativa & 0,00 & 0,00 & 0,00 & 0,00 & 0,10 & 0,0026 & 0,0 & 0,00 & 0,00 & 0,00 & 0,10 & 0,0015 \\
\hline Caatinga nova & 0,00 & 0,00 & 1,00 & 0,0900 & 0,41 & 0,0106 & 0,0 & 0,00 & 0,00 & 0,00 & 1,41 & 0,0174 \\
\hline Pousio (1) & 0,00 & 0,00 & 0,08 & 0,0068 & 0,79 & 0,0205 & 0,0 & 0,00 & 0,00 & 0,00 & 0,87 & 0,0133 \\
\hline Pousio (2) & 0,00 & 0,00 & 0,03 & 0,0025 & 0,34 & 0,0088 & 0,0 & 0,00 & 0,00 & 0,00 & 0,37 & 0,0056 \\
\hline Palma cultivada & 0,81 & 0,1022 & 9,73 & 0,8387 & 19,66 & 0,5115 & 3,16 & 0,4264 & 0,00 & 0,00 & 33,36 & 0,5103 \\
\hline Palma cultivada & 0,05 & 0,0063 & 4,98 & 0,4293 & 9,84 & 0,2560 & 0,53 & 0,0715 & 0,00 & 0,00 & 15,40 & 0,2355 \\
\hline
\end{tabular}

* 1) Do preparo do solo até o plantio (dezembro-janeiro); 2) Do fim do estádio 1 até 30 dias após o plantio (fevereiro); 3) Do fim do estádio 2 até 60 dias após o plantio (março-abril); 4) Do fím do estádio 3 até 180 dias após o plantio (maio-outubro) e 5) Do fim do estádio 4 até 210 dias após o plantio (novembro)

Tabela 4. Valores da razão de perdas de solo corrigidos pelo parâmetro erosividade da chuva $\left(\mathrm{EI}_{30}\right)$ e do parâmetro uso e manejo do solo (C)

\begin{tabular}{|c|c|c|c|c|c|c|}
\hline \multirow{2}{*}{ Cobertura vegetal } & \multicolumn{6}{|c|}{ Estádio de desenvolvimento das culturas* } \\
\hline & 1 & 2 & 3 & 4 & 5 & $\mathrm{C}$ \\
\hline Parcela padrão & - & - & - & - & - & 1,0000 \\
\hline Caatinga nova & 0,0000 & 0,0120 & 0,0058 & 0,0000 & 0,0000 & 0,0178 \\
\hline Pousio (1) & 0,0000 & 0,0016 & 0,0112 & 0,0000 & 0,0000 & 0,0128 \\
\hline Pousio (2) & 0,0000 & 0,0072 & 0,0048 & 0,0000 & 0,0000 & 0,1200 \\
\hline Palma cultivada em nível & 0,0005 & 0,1029 & 0,1408 & 0,0086 & 0,0000 & 0,2528 \\
\hline
\end{tabular}

* 1) Do preparo do solo até o plantio (dezembro-janeiro); 2) Do fim do estádio 1 até 30 dias após o plantio (fevereiro); 3) Do fim do estádio 2 até 60 dias após o plantio (março-abril); 4) Do fim do estádio

3 até 180 dias após o plantio (maio-outubro) e 5) Do fim do estádio 4 até 210 dias após o plantio (novembro). 
no início do experimento, para posterior rebrotamento, permanecendo a parcela, durante os primeiros anos, mais exposta à ação do impacto das gotas de chuva que a Caatinga Nativa e, por conseguinte, ao aumento da erosão hídrica; resultados semelhantes foram relatados por Ramos \& Marinho (1981) e Albuquerque et al. (2002a).

No semi-árido do Nordeste do Brasil predominam os cultivos manuais e tração animal; apesar disso, o desmatamento indiscriminado, as práticas inadequadas de manejo do solo, como preparo morro abaixo, queimadas e utilização intensa da mecanização com implementos inadequados, podem agravar os processos de degradação do solo, com risco potencial de expansão das áreas degradadas já existentes na região. Unidades de solo localizadas sobre o embasamento cristalino, caracterizadas por baixos teores de matéria orgânica, baixa profundidade efetiva e horizonte $\mathrm{B}$ textural, não podem permanecer sem a proteção da cobertura vegetal, devido ao risco de atingirem severo estágio de degradação (Albuquerque et al., 2001).

\section{Fator práticas conservacionistas $(P)$}

$\mathrm{O}$ valor do fator práticas conservacionistas $(\mathrm{P})$, para palma cultivada morro abaixo, foi de 0,4616 . Analisando-se os valores de perda de solo na cultura da palma nas condições estudadas (Tabela 5), constatou-se que, na média do período de estudo (1983 a 1988), o plantio desta cultura em nível apresentou níveis de perda de solo inferiores $\left(15,40 \mathrm{tha}^{-1}\right)$ aos obtidos com o cultivo da mesma cultura morro abaixo $\left(36,36 \mathrm{t} \mathrm{ha}^{-1}\right)$; assim, o cultivo em nível contribuiu para reduzir em torno de 53,8\% das perdas de solo, quando comparado com o cultivo morro abaixo, corroborando com os resultados obtidos por Margolis (1985), Bertoni \& Lombardi Neto (1985) e Silva et al. (1989).

Tabela 5. Valores médios de perda de solo e do fator práticas conservacionistas $(\mathrm{P})$

\begin{tabular}{lcc}
\hline \multicolumn{1}{c}{ Sistemas de cultivo } & $\begin{array}{c}\text { Perdas de solo } \\
\mathrm{t} \mathrm{ha}^{-1}\end{array}$ & $\mathrm{P}$ \\
\hline Palma morro abaixo & 33,36 & 1,0000 \\
Palma em nível & 15,40 & 0,4616 \\
\hline
\end{tabular}

$\mathrm{O}$ valor de fator $\mathrm{P}$ para a palma forrageira cultivada morro abaixo $(0,4616)$ foi menor que o obtido para Caruaru, $\mathrm{PE}(0,64)$ por Margolis et al. (1985) e maior que o obtido em Glória do Goitá, PE (0,29) por Margolis \& Campos Filho (1981).

\section{CONCLUSÕES}

1. Por exigir apenas as informações do volume e da intensidade máxima da chuva em trinta minutos e dispensar o cálculo da energia cinética, o fator erosividade da chuva $\mathrm{PI}_{30}$, apresenta-se como fator de melhor aplicabilidade.

2. As parcelas com caatinga nativa, caatinga nova e cobertura morta, mostraram os menores valores do fator " $\mathrm{C}$ " representando, então, alternativas de controle da erosão, especialmente em áreas de risco de degradação.

3. Por sua eficiência e simplicidade, o cultivo em nível representa um importante instrumento no controle da erosão hídrica.

\section{LITERATURA CITADA}

Albuquerque, A.W. Determinação de fatores para a equação universal de perdas de solo nas condições de Sumé-PB. Piracicaba: Escola Superior de Agricultura Luiz de Queiroz, 1997. 100p. Tese Doutorado

Albuquerque, A.W.; Lombardi Neto; F. Srinivasan, V.S.; Cataneo A. Efeito do desmatamento da caatinga sobre as perdas de solo e água de um Luvissol em Sumé-PB. Revista Brasileira de Ciência do Solo, Viçosa, v. 25, p.121-128, 2001.

Albuquerque A.W.; Lombardi Neto, F.; Srinivasan, V.S.; Santos J.R Manejo da cobertura do solo sobre as sobre as perdas de solo e água de um Luvissol em Sumé-PB. Revista Brasileira Engenharia Agrícola e Ambiental, Campina Grande,PB, v. 6, p.136-141, 2002a.

Albuquerque, A.W.; Lombardi Neto, F.; Srinivasan, V.S.; Cataneo, A.; Santos, J.R Parâmetros erosividade da chuva, da enxurrada e da chuva-enxurrada correlacionados com as perdas de solo de um Luvissol. Revista Brasileira de Ciência do Solo, Viçosa, v. 26, p.695-703, 2002b.

Bertoni, J.; Lombardi Neto, F. Conservação do solo. Piracicaba: Livroceres, 1985. 368p.

Cadier, E.; Freitas, B.J. de.; Leprun, J.C. Bacia Experimental de Sumé: instalação e primeiros resultados. Recife: SUDENE, 1983. 87p. Série Hidrológica, 16

Catalince, J.R.B.; Margolis, E. Características das chuvas e correlação de índices de erosividade com as perdas de solo do Agreste de Pernambuco. Revista Brasileira de Ciência do Solo, Campinas, v.17, p.275-281, 1994.

Cataneo, A.; Castro Filho, C.; Acquarole, R.M. Programa para cálculo de índices de erosividade de chuvas. Revistas Brasileiras de Ciências do Solo, Campinas, v.6, p.236-239, 1982.

Chaves, I.B. de; Diniz, E.J. Erosividade das chuvas no Estado da Paraíba. In: Encontro Nacional de Pesquisa sobre Conservação do Solo, 3, Recife, 1981. Anais..., Campinas, Sociedade Brasileira de Ciência do Solo, 1981. p.136-147.

Denardim, J.E. Erodibilidade do solo estimada por meio de fatores físicos e químicos. Piracicaba, Escola Superior de Agricultura Luiz de Queiroz. 1991. 104p. Tese Doutorado

DeMaria, I.C.; Lombardi Neto, F. Razão de perdas de solo e fator C para sistemas de manejo da cultura do milho. Revista Brasileira de Ciência do Solo, Viçosa, v. 21, p.263-270, 1997.

FAO. Desarrollo sostenible de tierras aridas y lucha contra la desertificacion: Posición de la FAO. Rome, 1993. 30p.

Foster, G.R.; McCool, D.K.; Renato, K.G.; Moldenhauer, W.C. Conservation of the Universal Soil Loss Equation the SI metric units. Journal of Soil and Water Conservation, Baltimore, v.36, p.355-359, 1981.

Galindo, I.C.; Margolis, E. Tolerância de perdas de solos do Estado de Pernambuco. Revista Brasileira de Ciência do Solo, Campinas, v.13, p.95-100, 1989.

Graybill, F.A. An introdution to linear statistical model. New York: McGraw Hill, 1961. 684p.

Leprun, J.C. Manejo e conservação de solos do Nordeste. Recife: SUDENE, 1988.238p. 
Margolis, E. Determinação dos fatores da equação universal de perdas de solo para as condições de Caruaru-PE. Revista Brasileira de Ciência do Solo, Viçoça, v.9, p.165-169, 1985.

Margolis, E.; Campos Filho, O.P. Determinação dos fatores da equação universal de perdas de solo num Podzólico Amarelo de Glória do Goitá. In: Encontro Nacional sobre Conservação do Solo, 3. Recife, 1981. Anais... Recife: 1981. p. 239-250.

Margolis, E.; Galindo, I.C. de L.; Mello Neto, A.V. de. Comportamento de sistemas de cultivo da mandioca em relação à produção e às perdas por erosão. Revista Brasileira de Ciência do Solo, Viçosa, v.15, p.357-362, 1991.

Margolis, E.; A.C. Mello Neto. Observações gerais sobre as perdas por erosão na Zona Agreste de Pernambuco. Boletim Técnico do Instituto de Pesquisa Agrônomicas, Recife, n. 74, p. 1-19. 1977

Mendes, B.V. Desertificação do semi-árido. In: Seminário Sobre Desertificação no Nordeste, Recife, 1986. Trabalhos apresentados. Brasilia: Ministério do Desenvolvimento Urbano e do Meio Ambiente e Secretaria Especial do Meio Ambiente (SEMA), 1986. p.111-115.

Nearing, M.A.; Lane, L.J.; Alberts, E.E.; Laflen, J.M. Prediction technology for soil erosion by water: status and research needs. Soil Science Society of America Journal, Madison, v.54, p.1702-1711, 1990.
Owoputi, L.O.; Stolte, W.J. Soil detachment in the physically based soil erosion processes: A review. Transctions of the ASAE, St. Joseph, v.38, p.1099-1110, 1995.

Ramos, A.D.; Marinho, H.E. Estudo da erodibilidade de um solo Litólico sem cobertura vegetal e sob duas condições de pastagens nativa de caatinga. Sobral: EMBRAPA, 1981. 16p. Boletim de Pesquisa, 2

Reis, J.G. Desertificação no Nordeste. Recife: SUDENE, 1988. 40 p. SAS. Institute. SAS/STAT: guide for personal computers, version 6 Edition. Cary: SAS Institute, 1988. 378p.

Silva, I.de F. da; Campos Filho, O.R; Andrade, A.P. de; Campos Filho, O.R. Erodibilidade de seis solos do semi-árido paraibano obtida com chuva simulada e método nomográfico. Revista Brasileira de Ciência do Solo, Campinas, v.10, p. 283-287, 1986. Revista Brasileira de Ciência do Solo, Campinas, v.13, p.111-115, 1986.

Silva, I.de F. da; Campos Filho, O.R; Andrade, A.P. de; Coêlho, E.A.C; Diniz, E.J. Influência do cultivo isolado e do consórcio sobre as perdas de solo e água numa Terra Roxa estruturada. Revista Brasileira de Ciência do Solo, Campinas, v.13, p.111$115,1989$.

Wischmeier, W.H.; Smith, D.D. Predicting rainfall erosion losses: A guide to conservation planning. Washington: USDA, 1965. 52p. Agricultural Handbook, 282

Wischmeier, W.H; Smith, D.D. Predicting rainfall erosion losses: A guide to conservation planning. Washington: USDA, 1978. 58p. Agricultural Handbook, 537 